\title{
Controlled cooling of an aluminum alloy casting based on 3D printed rib reinforced shell mold
}

\author{
Hao-long Shangguan ${ }^{1}$, *Jin-wu Kang ${ }^{1}$, Ji-hao Yi ${ }^{1}$, Cheng-yang Deng ${ }^{1}$, Yong-yi Hu ${ }^{1}$, and Tao Huang ${ }^{2}$ \\ 1. School of Materials Science and Engineering, Key Laboratory for Advanced Materials Processing Technology, Tsinghua University, \\ Beijing 100084, China \\ 2. Beijing DRUCK Technology Development Co. Ltd., Beijing 100029, China
}

\begin{abstract}
D printing technology has been used for sand molding and core printing, but they simply substitute the traditional molding and core making method without changing the shape or size of the sand mold (core) and their dense structure. In this study, a new type of hollow mold based on 3D printing is presented. The new type of mold is a rib reinforced thickness-varying shell mold. This mold design can realize the controlled cooling of castings, i.e., different cooling rates at different areas, and improve the temperature uniformity of a casting after its solidification. Therefore, the performance of castings can be improved and their residual stress and deformation can be reduced. This kind of new mold was applied to a stress frame of A356 aluminum alloy. The 3D printed rib reinforced thickness-varying shell mold was compared with the traditional dense mold, and the castings obtained by these two kinds of molds were also compared. The experimental results showed that the rib reinforced shell mold increased the cooling rate of the casting by $30 \%$, tensile strength by $17 \%$, yield strength by $11 \%$, elongation by $67 \%$, and decreased its deformation by $43 \%$, while sand consumption was greatly reduced by $90 \%$.
\end{abstract}

Key words: rib reinforced thickness-varying shell mold; 3D printing; casting; solidification; cooling
CLC numbers: TG146.21
Document code: $\mathrm{A}$
Article ID: 1672-6421(2018)03-210-06

$\mathrm{T}$ The production of castings depends on molds. Although diversified molding techniques and mechanization of molding have been realized ${ }^{[1,2]}$, the mold design is mainly of a dense structure. This kind of dense structure makes it difficult to control the cooling performance of molds during the casting process. Therefore, the cooling performance of traditional molds mainly depends on their thermal absorption, i.e., the casting is chilled by the cold mold just after pouring of the melt, and then, its cooling rate declines because the heat absorption capacity of the traditional dense mold decreases. This results in a very slow cooling of castings and significantly decreases production efficiency. To improve production efficiency, earlier shakeout can be used to cool castings quickly in air. However, this leads to the significant residual stress and deformation and even cracks in castings. The sand use in dense molds

\section{*Jin-wu Kang}

Male, born in 1970, Associate Professor, Ph.D. His research interests maily focus on the modelling and simulation of casting process and solidification. His academic research has led to the publication of more than 160 papers in journals such as Metallurgical and Materials Transactions, Materials Science and Engineering, and so on.

E-mail: kangjw@tsinghua.edu.cn

Received: 2017-12-21; Accepted: 2018-03-05 is substantial, usually several times heavier than the corresponding casting. This accounts for 70 million tons of waste sand in China every year, which exerts a considerable environmental pressure ${ }^{[3,4]}$.

Recently, advancements have been made in the field of three-dimensional (3D) printing, which has been applied in the casting field ${ }^{[5-8]}$. The applications of 3D printing technology to the field of casting mainly include prototype or pattern printing ${ }^{[9,10]}$, part printing ${ }^{[11,12]}$, and sand mold and core printing ${ }^{[13-17]}$. However, the applications of $3 \mathrm{D}$ printing to sand mold and core printing simply substitute the traditional molding and core making method without changing the shape or size of the sand mold (core) and their dense structure. Essentially, 3D printing not only provides a substitution method for traditional manufacturing but also revolutionizes the topological structure design of products ${ }^{[18-22]}$. 3D printing technology can also bring new elements to casting design and mold design in the casting industry. Kang et al. proposed the application of a hollow mold to aluminum alloy castings according to the idea of a shell-truss mold based on 3D printing technology, and achieved outstanding results ${ }^{[23-25]}$. But, the shell thickness is uniform, which is not suitable for complicated castings with different section thicknesses. 
Based on the ideology of a 3D printed hollow mold, the rib reinforced thickness-varying shell mold was proposed and tested in this study. Controlled cooling was realized during the casting process, and then the casting's mechanical properties were improved.

\section{Rib reinforced thickness-varying shell mold}

Rib reinforced thickness-varying shell mold was proposed to solve the difficulty of cooling control in a dense mold. This mold is composed of a thickness-varying shell with a cavity for the casting and rib structure for support (Fig. 1). Shell thickness is variable to adapt to the thickness variation of a casting, i.e., the shell is thin at the thin casting positions and is thick at the thick casting positions. Further, various patterns of rib structures can be designed to reinforce the shell. Ribs along the $\mathrm{X}, \mathrm{Y}$, and $\mathrm{Z}$ directions formed a net structure on the shell surface. This rib reinforced thickness-varying shell mold structure was difficult to achieve using traditional molding techniques, but, it could be manufactured using 3D printing technology.

(a)

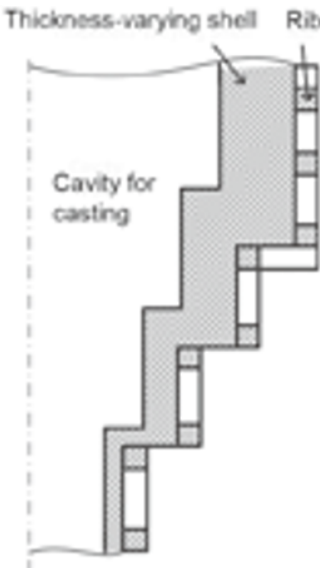

(b)

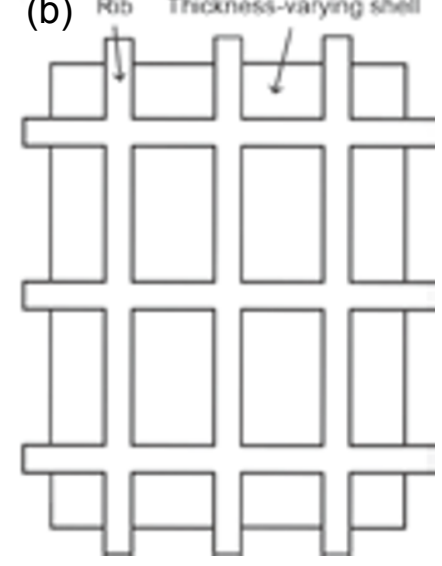

Fig. 1: Schematic diagram of rib reinforced thickness-varying shell mold: (a) front viewsection, (b) side view

(a)

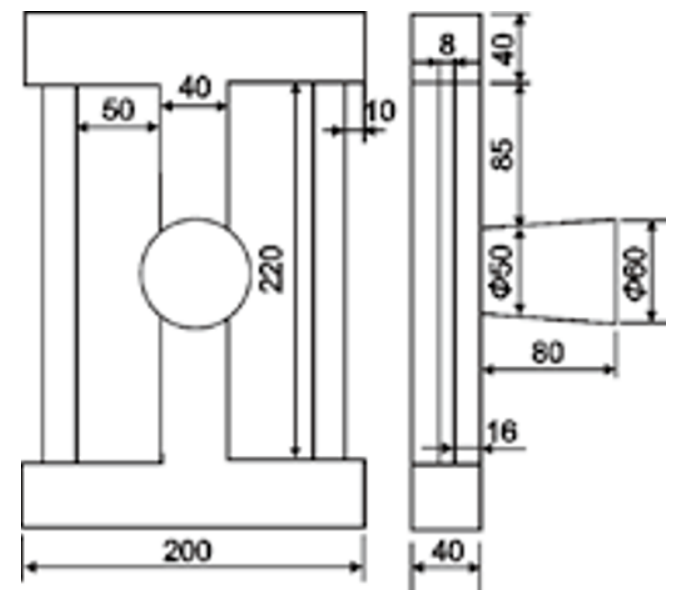

The rib reinforced thickness-varying shell mold has to constrain high-temperature liquid metal. Therefore, the proper design of shell thickness and section area of ribs are very important. The shell mold is affected by the hydrostatic pressure of the molten metal during the casting process as well as the weight of the casting after its solidification. Furthermore, a mold is sensitive to heating by the casting, and its strength decreases as temperature increases. All of these factors should be considered in shell thickness design. Hence, shell thickness can be calculated as follows:

$$
d>\left(\frac{\int \rho g h S_{\mathrm{h}} d h}{\sigma(T)}-S_{\mathrm{a}}\right) / l_{\min }
$$

Moreover, the shell strength is larger than the maximum molten metal hydraulic pressure.

$$
\sigma(T)>\rho g h_{\max }
$$

where $d$ is the shell thickness, $l_{\min }$ is the perimeter of minimum horizontal section of shell, $\sigma(T)$ is the shell strength varying with temperature, $h$ is the height of the melt, $h_{\max }$ is the maximum height of the melt, $\rho$ is the density of the melt, $g$ is the gravitational acceleration, $S_{\mathrm{a}}$ is the total horizontal section area of the shell-constraining ribs, and $S_{\mathrm{h}}$ is the horizontal section area of the mold at the height of $h$.

\section{Experimental procedures}

The proposed rib reinforced thickness-varying shell structure was applied to a stress frame casting, as shown in Fig. 2. The designed mold is composed of a shell and ribs enforcing the shell, as shown in Fig. 2(b).

The rib reinforced shell mold and the traditional dense mold were printed using an ExOne-Smax 3D printing machine. In 3D printing, $1.6 \%-1.8 \%$ furan resin was used and $0.2 \%$ curing agent was added. These molds had no parting line and were unit pieces. The shell was $10 \mathrm{~mm}$ thick and the extrusion of ribs was $5 \mathrm{~mm}$ high and $5 \mathrm{~mm}$ thick. The ribs were at an interval of $13 \mathrm{~mm}$. Two kinds of 3D printed sand molds: traditional dense mold and rib reinforced mold are shown in Fig. 3. For the convenience of sand cleaning in the mold cavity, small holes were designed at

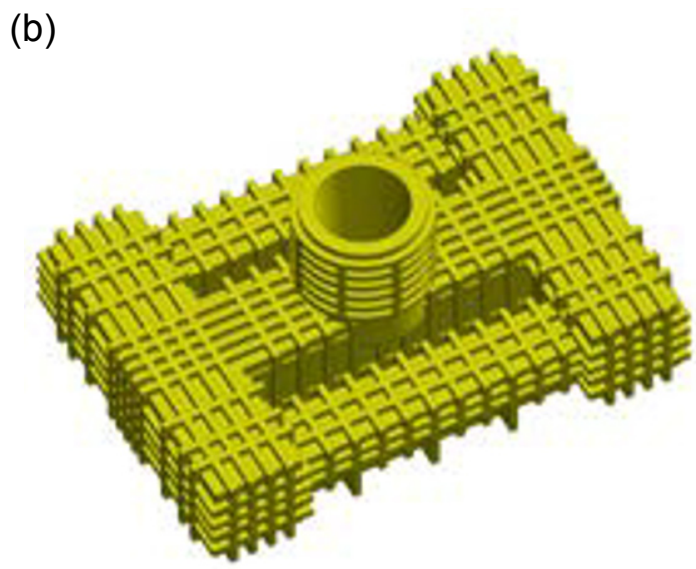

Fig. 2: Rib reinforced thickness-varying shell mold for stress frame casting: (a) geometry of stress frame casting (unit: $\mathrm{mm}$ ), (b) rib reinforced shell mold 

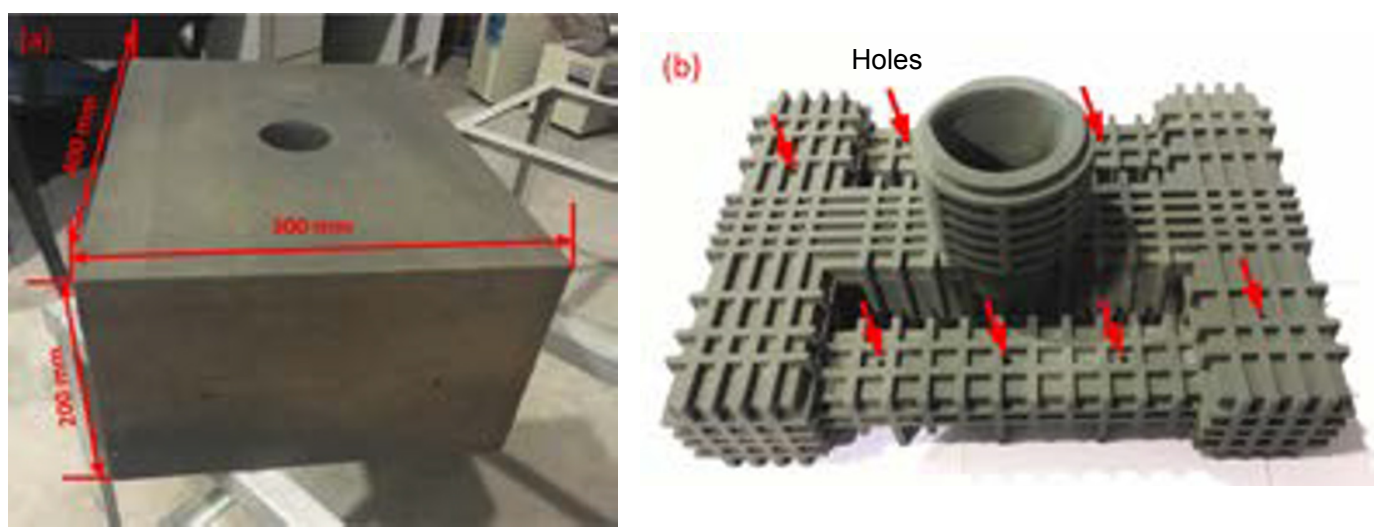

Fig. 3: Two kinds of 3D printing sand molds: (a) traditional dense sand mold, (b) rib reinforced shell sand mold

positions where it is difficult for sand cleaning, as shown in Fig. 3(b). Further, the narrow channels and cavities of these sand molds were examined with an endoscope to make sure there was no residual loose sand inside these molds. This new mold only required $3 \mathrm{~kg}$ of mold sand, compared to $30 \mathrm{~kg}$ required by the dense mold. Therefore, $90 \%$ sand was saved.

The molten A356 aluminum alloy whose composition is listed in Table 1 was poured in the mold. Its liquidus and solidus are $616{ }^{\circ} \mathrm{C}$ and $556{ }^{\circ} \mathrm{C}$, respectively. The pouring temperature was $700^{\circ} \mathrm{C}$. Temperatures of the casting were measured with
K-type sheathed thermocouples, as shown in Fig. 4. In the casting process, the temperature of the thick rod was monitored, after its temperature was lower than the liquidus, and the liquid level of the riser came to be stable, which indicated the end of feeding, then, cold air was blown toward the sand mold surface corresponding to the thick rod of the casting till shakeout. Thus, the late solidification stage of the thick rod was quickened to refine grains and then its fast cooling is helpful for decreasing the temperature difference between thick and thin rods so as to reduce its residual stress and deformation after solidification.

Table 1: Chemical composition of A356 Al alloy (wt.\%)

\begin{tabular}{ccccccccc} 
Si & $\mathrm{Mg}$ & $\mathrm{Fe}$ & $\mathrm{Cu}$ & $\mathrm{Zn}$ & $\mathrm{Mn}$ & $\mathrm{Ti}$ & $\mathrm{Al}$ \\
\hline $6.5-7.5$ & $0.25-0.45$ & 0.12 & 0.05 & 0.05 & 0.05 & $0.08-0.20$ & Balance
\end{tabular}
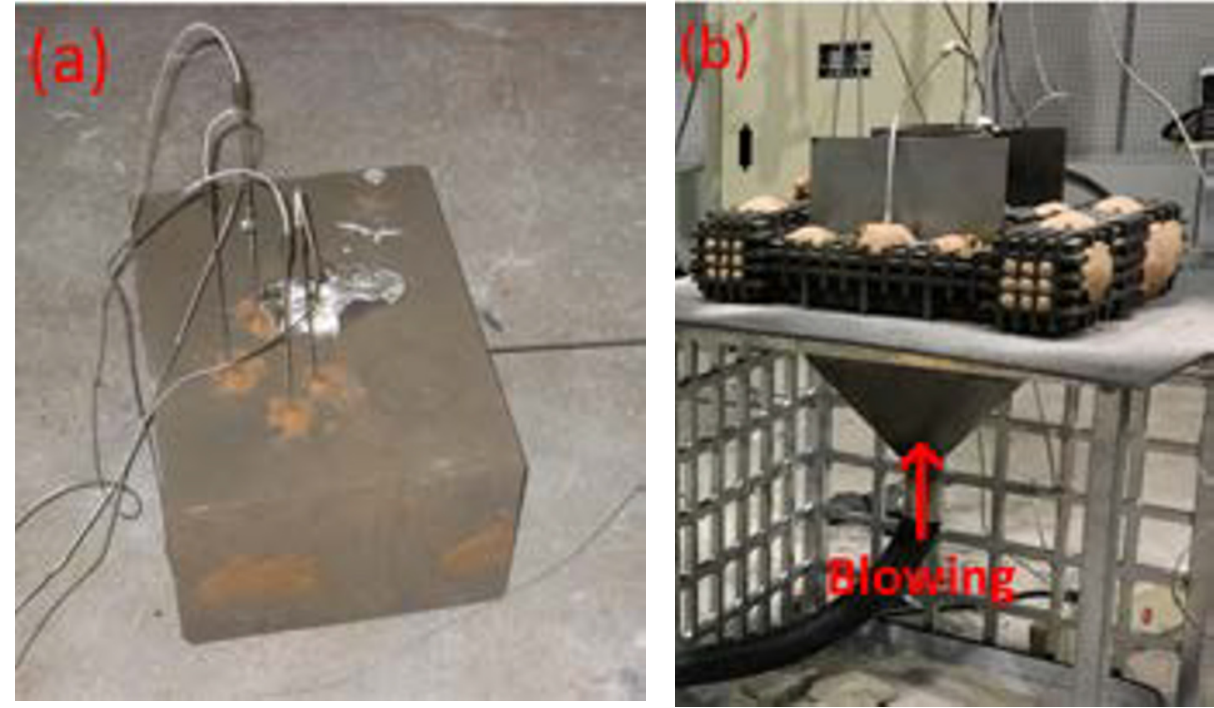

Fig. 4: Onsite pouring experiments: (a) traditional dense sand mold (natural cooling), (b) rib reinforced shell sand mold (controlled cooling)

The shakeout temperature was $200{ }^{\circ} \mathrm{C}$. The surface roughness of the casting after the shakeout was measured using the FORM Talysurf PGI800 contour graph device. The 3D morphology was tested using a HSCAN330 3D scanner, and then deformations were deduced by the comparison of the actual geometry and the designed one. Tensile samples were prepared from the thick rod of the casting according to the GB/T228.1-2010 standards. Tensile experiments were performed on a WDW-10E tester. The microstructures of these two castings were observed using a ZEISS AXIO ScopeA1 metalloscope. 


\section{Results and discussion}

\subsection{Comparison of solidification and cooling of castings}

The cooling process of a casting in a traditional dense mold is uncontrollable because of its thick wall and cubic shape. However, the cooling process of the casting in the proposed mold can be controlled because of the hollow-out structure. The comparison of the controlled cooling curve of the casting poured in the rib reinforced shell mold and the natural cooling of the casting in a traditional dense mold is shown in Fig. 5. It can be seen from Fig. 5(a) that the cooling rate of the casting in the rib reinforced mold was higher than that in the traditional dense mold. It took the rib reinforced shell mold less cooling time $(3,800 \mathrm{~s})$ than the traditional dense mold casting $(5,700 \mathrm{~s})$ to shakeout at $200{ }^{\circ} \mathrm{C}$. The cooling efficiency increased by $30 \%$. This was attributed to the fact that the shell of the new mold

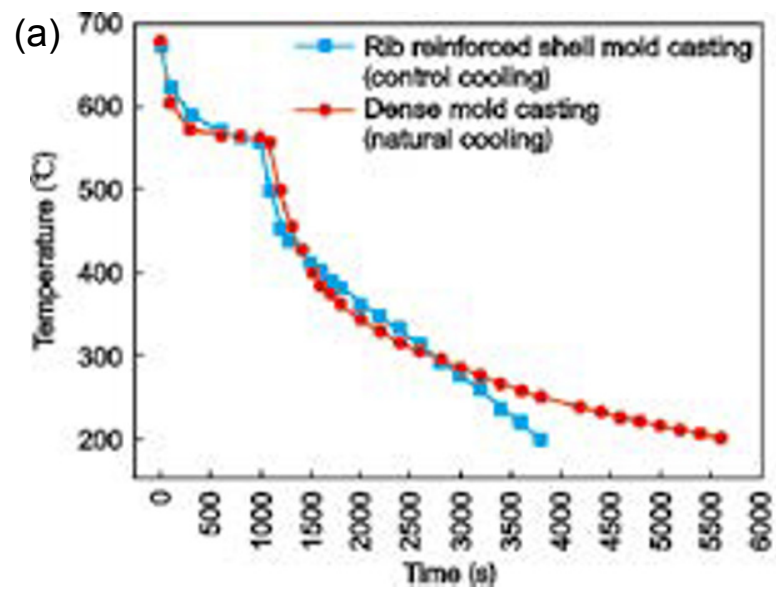

always stayed at a high surface temperature, which resulted in high heat transfer efficiency between it and air. Thus, the cooling efficiency of the casting was higher. For the dense mold casting, the casting cooled very slowly in the late period of the casting process because of the approaching saturation of heat storage of the mold. The blowing air on the shell corresponding to the thick rod accelerated its cooling at $900 \mathrm{~s}$, at which time the solidification of the thick rod had not been fully completed. Therefore, the forced cooling enhanced the solidification of the thick rod, but it didn't influence the feeding of the casting because it was at the late stage of solidification. The solidification time of the thick rod is shortened by $110 \mathrm{~s}$, or $10 \%$. The chilling effect of blowing air was in favor of the refining of microstructure. In the subsequent cooling stage after solidification, the enforced cooling decreased the temperature difference between the thick and thin rods. Consequently, the thermal stress and the deformation of the casting could be decreased.

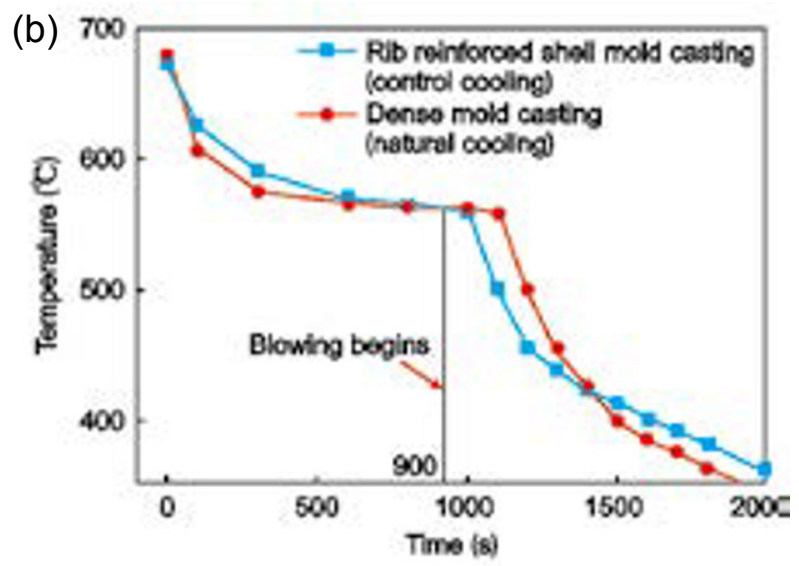

Fig. 5: Cooling curves of the traditional and rib reinforced shell sand mold for thick rod: (a) comparison of cooling curves, (b) enlargement of figure (a) to emphasize solidification period

\subsection{Casting quality}

The castings obtained by 3D printed sand molds both have good surface quality. The picture of the casting with $3 \mathrm{D}$ printed sand mold after shakeout is shown in Fig. 6. Good mold filling was observed in the casting, no burr or flashing appeared. The surface roughness of the casting after the shakeout was measured using the FORM Talysurf PGI800 contour graph device, which reached level four.

\subsection{Deformation of castings}

A comparison of the deformation of these two castings after 3D scanning is shown in Fig. 7. The castings by the dense mold, as shown on the left half of Fig. 7, exhibited larger deformation than that of the rib reinforced shell mold shown on the right half of Fig. 7. The length difference of thick and thin rods in the dense mold casting was $0.7 \mathrm{~mm}$, while that in the rib reinforced shell mold was only $0.4 \mathrm{~mm}$. The deformation was $43 \%$ lower for the rib reinforced shell mold casting. With the controlled cooling in the case of rib reinforced shell mold, the temperature gradient between thick and thin rods decreased, thus, the deformation of the casting was reduced.

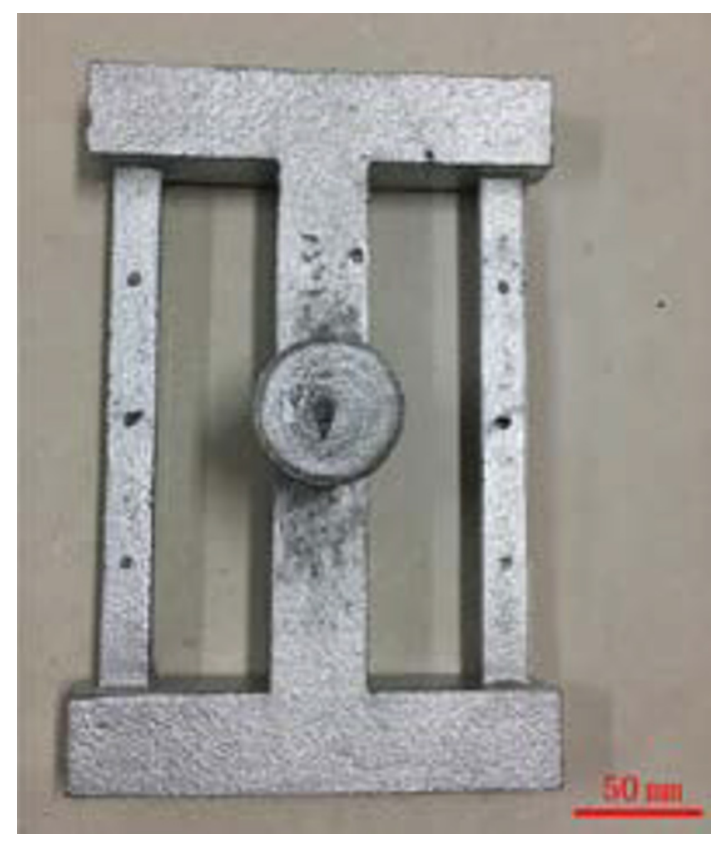

Fig. 6: Casting obtained from 3D printed rib enforced sand mold 


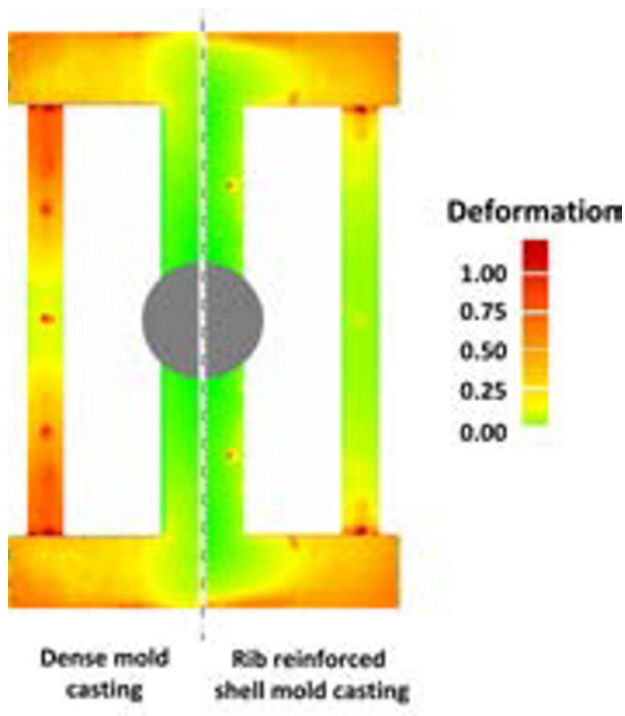

Fig. 7: Comparison for deformation of castings by dense mold and rib reinforced shell mold (unit: $\mathrm{mm}$ )

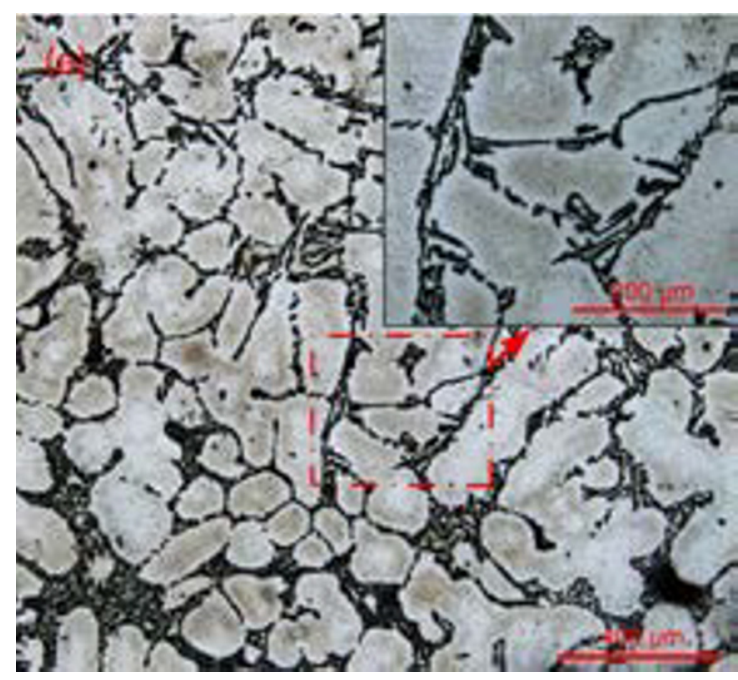

Fig. 8: Microstructures of thick rod by dense mold (a) and rib reinforced shell mold (b)

Table 2: Mechanical properties of these two castings

\begin{tabular}{cccc} 
Si & $\boldsymbol{R}_{\mathrm{m}}(\mathrm{MPa})$ & $\boldsymbol{R}_{\mathrm{p} 0.2}(\mathrm{MPa})$ & $\boldsymbol{A}(\%)$ \\
\hline Dense mold (natural cooling) & 107 & 83 & 1.2 \\
Rib reinforced shell mold (controlled cooling) & 125 & 92 & 2.0
\end{tabular}

\section{Conclusions}

(1) A new rib reinforced thickness-varying shell mold based on 3D printing was proposed and applied in an A356 stress frame aluminum alloy casting, which realized controlled cooling. Compared with the traditional dense mold, the new mold increased the cooling efficiency of the castings by $30 \%$ and reduced sand use by $90 \%$. The rib reinforced shell mold has the potential for whole scale controlled cooling of castings, and to be helpful for the achievement of a smart and green casting process.

(2) The deformation of the casting by the new mold was $43 \%$

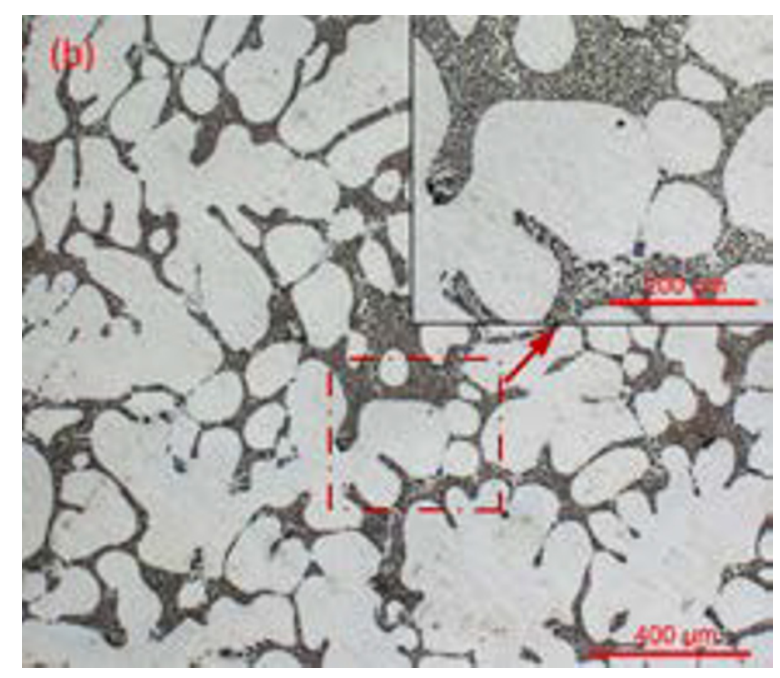

\subsection{Microstructure and properties}

The microstructures of the A356 aluminum alloy castings in the case of both dense mold and rib reinforced shell mold are shown in Fig. 8. It can be seen that the eutectic microstructure of $\alpha(\mathrm{Al})$ and silicon among the primary $\alpha(\mathrm{Al})$ dendrites by the new mold with air blowing was finer than that by the dense mold. This was attributed to the good heat release capability and the forced cooling of the rib reinforced shell mold. The refining of the eutectic microstructure contributed to the improvement of the mechanical properties of the casting.

The mechanical properties of the A356 aluminum alloy castings in the case of the dense mold casting and the rib reinforced shell mold casting are shown in Table 2. Obviously, the casting by the rib reinforced shell mold exhibited better mechanical properties than that by the dense mold. The tensile strength, yield strength, and elongation increased by $17 \%, 11 \%$, and $67 \%$, respectively. 
[2] Liu Jiang. The shell molding process study for mass production of single-cylinder diesel engine crankshaft. Applied Mechanics and Materials, 2011,44-47: 284-288.

[3] Long Wei, Fan Zitian. The situation and progress of the recycling of old sand. China Foundry Machinery \& Technology, 2012 (2): 1-5. (In Chinese)

[4] Xing Wanting, Liu Yue, Xin Qibin, et al. Research progress and application of old sand regeneration. Foundry, 2015, 64(8): 735739. (In Chinese)

[5] Thomas B, John U. 3D, SF and the future. Futures, 2013, 50: 25-34.

[6] Kirleis M A, Simonson D, Charipar N A, et al. Laser embedding electronics on 3D printed objects. In: Proc. SPIE - The International Society for Optical Engineering, California, 2014, 8970: 1-7.

[7] Kang Jinwu, Ma Qiangxian. The role and impact of 3D printing technologies in casting. China Foundry, 2017, 14(3): 157-168.

[8] Dutta B, Froes F H. Titanium Powder Metallurgy. Science, Technology and Applications. Elsevier, 2015: 447-468.

[9] Sun D, Xu X C, Wang D H, Liu K F, et al. Rapid investment casting process for impeller based on 3D printing technology. Special Casting \& Nonferrous Alloys, 2016, 36(11): 1172-1174. (In Chinese)

[10] Li S P, Zheng D Q, Wang H F. Application of 3D printed investment casting technology in the manufacturing of engines. Agro Food Industry Hi Tech, 2017(28): 1419-1421.

[11] Chunze $\mathrm{Y}$, Liang $\mathrm{H}$, Ahmed $\mathrm{H}$, et al. Evaluation of light-weight AISi10Mg periodic cellular lattice structures fabricated via direct metal laser sintering. Journal of Materials Processing Technology, 2014, 214: 856-864.

[12] Druschitz A, Williams C, Snelling D, et al. Additive manufacturing supports the production of complex castings. 143rd Annual Meeting and Exhibition, USA: Shape Casting, 2014: 51-57.

[13] Snelling D, Li Q, Meisel N, et al. Lightweight Metal Cellular Structures Fabricated via 3D Printing of Sand Cast Moulds. Advanced Engineering Materials, 2015, 17(7): 923-932.

[14] Snelling $D$, Blount $H$, Charles $F$, et al. The effects of $3 D$ printed molds on metal castings. In: Proc. 24th International SFF
Symposium - An Additive Manufacturing Conference, SFF, 2013: 827-845.

[15] Casalino G, Filippis L.A.C. D, Ludovico A. A technical note on the mechanical and physical characterization of selective laser sintered sand for rapid casting. Journal of Materials Processing Technology, 2005, 166: 1-8.

[16] Wood K, Ravi S. Design Considerations for Three Dimensional Printed Cores and Molds. In: Proc. 119th Metal casting Congress, Columbus, 2015, 24-29.

[17] Crommert S V D, Seitz, S, Esser, K K., et al. Sand, die and investment cast parts via the $S L S \otimes$ selective laser sintering process. In: Proc. SPIE - The International Society for Optical Engineering, Munich, 1997, 3102: 95-105.

[18] LI Y, Ola H, Denis C, et al. Additive Manufacturing of Metal Cellular Structures: Design and Fabrication. JOM, 2015, 67(3): 608-615.

[19] Adithya C, Ju J. Continuum model for effective properties of orthotropic octet-truss lattice materials. In: Proc. ASME International Mechanical Engineering Congress and Exposition, Montreal, 2014: 1-5.

[20] Chen Y. 3D Texture Mapping: A Microstructure Design Method for Rapid Manufacturing. Computer-Aided Design \& Applications, 2007, 4(6): 761-771.

[21] Chen Y, Wang S L. Computer-aided Product Design with Performance-Tailored Mesostructures. Computer-Aided Design \& Applications, 2008, 5(1-4): 1-11.

[22] Guido A.O.A, Detmar Z. Design for Additive ManufacturingElement transitions and aggregated structures. CIRP Journal of Manufacturing Science and Technology, 2014, 7: 20-28.

[23] Kang Jinwu, Shangguan Haolong, Deng Chenyang. New mold of non-dense structure. China Patent, 109313716, 2015. (In Chinese)

[24] Kang Jinwu, Shangguan Haolong, Hu Yongyi. New mold of double shell structure. China Patent, 101255666, 2016. (In Chinese)

[25] Shangguan Haolong, Kang Jinwu, Deng Chenyang, et al. 3D-printed shell-truss sand mold for aluminum castings, Journal of Materials Processing Technology, 2017, 250: 247-253. 